\title{
MICADAS: ROUTINE AND HIGH-PRECISION RADIOCARBON DATING
}

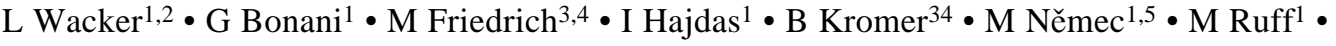 \\ M Suter $^{1} \bullet \mathrm{H}-\mathrm{A}$ Synal $^{1} \bullet \mathrm{C}$ Vockenhuber $^{1}$
}

ABSTRACT. The prototype mini carbon dating system (MICADAS) at ETH Zurich has been in routine operation for almost 2 yr. Because of its simple and compact layout, setting up a radiocarbon measurement is fast and the system runs very reliably over days or even weeks without retuning. The stability of the instrument is responsible for the good performance in highestprecision measurements where results of single samples can be reproduced within less than $2 \%$. The measurements are described and the performance of MICADAS is demonstrated on measured data.

\section{INTRODUCTION}

The mini carbon dating system (MICADAS) at ETH Zurich was built 4 yr ago (Synal et al. 2007), based on principles already used at the 0.5MV system called TANDY (Synal et al. 2000). In the first $2 \mathrm{yr}$, MICADAS was mainly used for experimental development, while routine radiocarbon measurements were still performed on the large 6MV EN-tandem, as they had been successfully done for almost $30 \mathrm{yr}$ (Suter et al. 1984a; Bonani et al. 1987). During the last 2 yr, we made a smooth transition of routine ${ }^{14} \mathrm{C}$ measurements from the large accelerator to the MICADAS, mainly because the latter requires little maintenance and runs unattended. Here, we present our experience with the MICADAS in routine operation from the past 2 yr. We were also encouraged to test the MICADAS for highest-precision measurements, because already the first measurements had shown that it is possible to measure samples very reproducibly (Synal et al. 2007).

\section{METHOD}

\section{Sample Preparation}

Most samples were graphitized on a semi-automated system after sample cleaning and combustion in closed quartz tubes (Hajdas et al. 2004). The system was built $8 \mathrm{yr}$ ago and produces about $2 \mathrm{mg}$ of graphite deposited on $7 \mathrm{mg}$ of iron. This is a rather large amount optimized for the measurement on the large 6MV tandem accelerator, which is equipped with a negative ion source where the samples are moved during sputtering to avoid cater formation (Bonani et al. 1987). On the other hand, only 1-1.5 mg of graphite are typically used for a measurement using MICADAS.

The wood samples for high-precision measurements as shown below were cleaned with a base-acidbase-acid bleaching procedure (Němec et al. 2010) and then graphitized on a recently developed system that is fully automated (Wacker et al. 2010b). The graphitization system is directly coupled to an elemental analyzer (EA) and runs without any user interaction after the samples are loaded into the EA and the iron catalyst is inserted into individual reactors. The amount of graphite has been adapted for the measurement on MICADAS (1 $\mathrm{mg}$ of graphite on $3.5 \mathrm{mg}$ of $\mathrm{Fe}$ ).

Some additional samples were also prepared at the Academy of Sciences in Heidelberg. These samples were tube combusted and graphitized on a semi-automated system, similar to the one at ETH

\footnotetext{
${ }^{1}$ Ion Beam Physics, ETH Zurich, 8093 Zurich, Switzerland.

${ }^{2}$ Corresponding author. Email: wacker@phys.ethz.ch.

${ }^{3}$ Heidelberg Academy of Sciences, 69120 Heidelberg, Germany.

${ }^{4}$ Institute of Botany, University of Hohenheim, 70593 Stuttgart, Germany.

${ }^{5}$ Department of Chemistry and Biochemistry, University of Bern, 3012 Bern, Switzerland.
}

(C) 2010 by the Arizona Board of Regents on behalf of the University of Arizona Proceedings of the 20th International Radiocarbon Conference, edited by A J T Jull RADIOCARBON, Vol 52, Nr 2-3, 2010, p 252-262 
(Unkel 2006). All samples were pressed pneumatically into a 1-mm hole of the sample holders with $250 \mathrm{MPa}$ (equivalent to $200 \mathrm{~N}$ on a pin with $1 \mathrm{~mm}$ diameter).

\section{Measurements}

We have now measured more than 4000 solid samples and 1000 gaseous samples in the first 18 months of routine operation on the MICADAS. The machine runs very reliably for days without having any problems. MICADAS is designed to run unattended and features an automatic monitoring system. The hardware and the measured results are continuously checked, and in case of any anomaly, the automated measurement is stopped and/or the operator is informed by email or a short message on the mobile phone.

The main system parameters are given in Table 1 . The source is equipped with a prototype sample changer that allows changing cassettes with 20 positions without interruption of the measurement. It is also possible to measure small $\mathrm{CO}_{2}$ samples ( $<100 \mu \mathrm{g}$ carbon) directly, without having to graphitize the samples (Ruff et al. 2007, 2010).

Table 1 Main parameters for MICADAS measurements.

\begin{tabular}{ll}
\hline Parameter & Value \\
\hline Graphite & $0.9 \mathrm{mg} / 2 \mathrm{mg}^{\mathrm{a}}$ \\
Iron catalyst & $3.5 \mathrm{mg} / 7 \mathrm{mg}^{\mathrm{a}}$ \\
$\mathrm{C}^{-}$current $(\mathrm{LE})$ & $20-40 \mu \mathrm{A}$ \\
Source potential & $38 \mathrm{kV}$ \\
Terminal voltage & $195 \mathrm{kV}$ \\
Stripper gas & $\mathrm{N}_{2}$ \\
Transmission $\left({ }^{12} \mathrm{C}\right)$ & $43 \%$ \\
Measured ratio $\left(1 \mathrm{~F}^{14} \mathrm{C}\right)$ & $1.066 \times 10^{-12}$ \\
Precision (modern) & \\
routine & $3-4 \% \mathrm{o}$ \\
high-precision & $1.5-2 \% \mathrm{o}$ \\
\hline
\end{tabular}

${ }^{\mathrm{a}}$ Depending on the graphitization system, see text.

After turning on the ion source and the magnets, the system is left to stabilize for $2-3 \mathrm{hr}$. The tuning of the system takes about 30 min or less, even for highest-precision measurements. This is mainly because the only adjustable steering and focusing options for the ion beam are inside the ion source. The system is normally set up on Monday and is then left running without or only minor retuning over the rest of the week or even longer. Measurements were carried out with ${ }^{12} \mathrm{C}$ currents between 20 and $40 \mu \mathrm{A}$ on the low-energy side. The transmission $\left({ }^{12} \mathrm{C}^{-} /{ }^{12} \mathrm{C}^{+}\right)$was always very stable at $43.1 \pm$ $0.4 \%$ (based on all OXII standards measured during the first half of 2009; see Figure 1).

A typical ${ }^{14} \mathrm{C}$ measurement on the MICADAS at ETH Zurich is done as follows: a cassette has 20 samples, including 3 standards and 2 blanks; all samples of a cassette are measured at least 5-6 times. A single measurement is subdivided into 10 cycles of $45 \mathrm{~s}$ each. For high-precision measurements, we used 4-6 standards and at least 3 blanks and the measurement time of 30-60 min per sample was increased to $2-3 \mathrm{hr}$ by extending the cycle time to $60 \mathrm{~s}$ and by measuring each sample 10 15 times.

The recorded data set for each measurement consists of the number of ${ }^{14} \mathrm{C}$ counts, the measurement time, high-energy currents of ${ }^{12} \mathrm{C}^{+},{ }^{13} \mathrm{C}^{+}$, and also the ${ }^{13} \mathrm{C}^{+}$current of broken-up ${ }^{13} \mathrm{CH}^{-}$molecules $\left({ }^{13} \mathrm{C}_{\mathrm{H}}\right)$, injected together with ${ }^{14} \mathrm{C}$ into the stripper (Suter et al. 1984b; Synal et al. 2007). The ${ }^{14} \mathrm{C}$ 


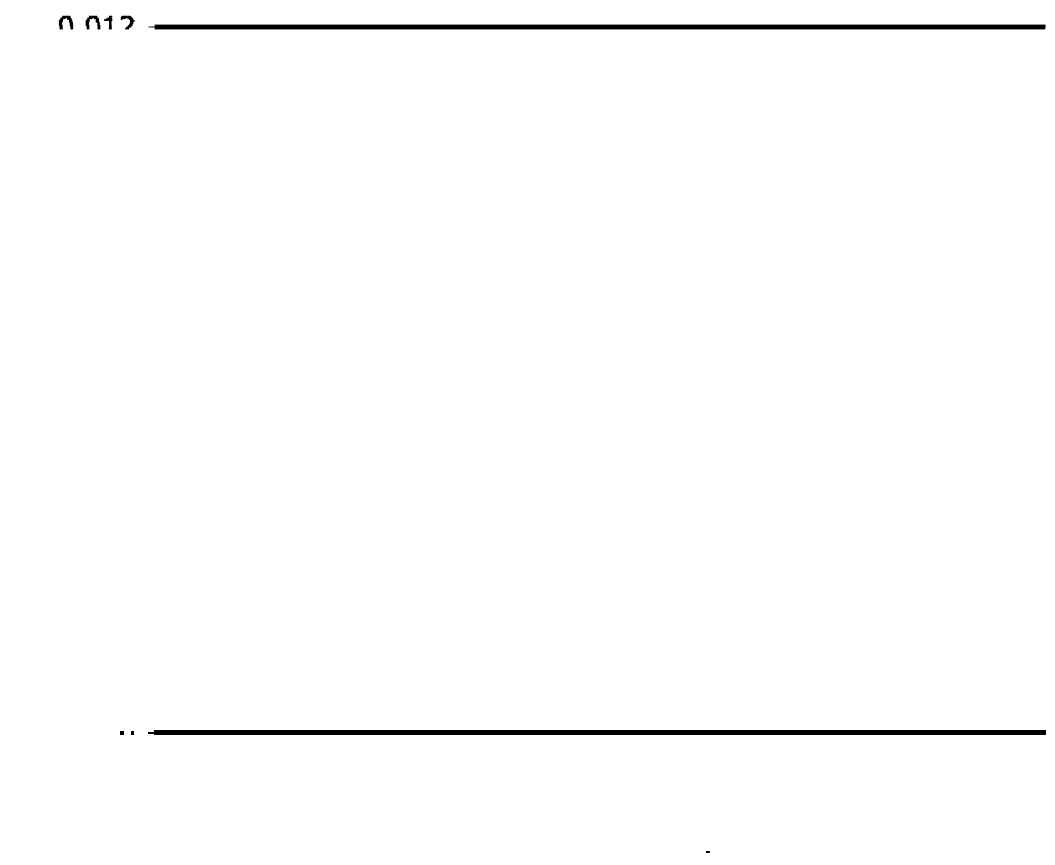

Figure 1 Correlation between the measured ${ }^{14} \mathrm{C} /{ }^{12} \mathrm{C}$ ratio and the ${ }^{13} \mathrm{C}$ current from the molecule breakup divided by the ${ }^{12} \mathrm{C}$ current for all blank samples measured in 2009 is shown. The slope of the plotted lines corresponds to our applied molecular correction $\left(450 \mu \mathrm{A}^{-1} \mathrm{~s}^{-1}\right.$, see text). An average blank sample lies on the solid line, and corresponds to a ${ }^{14} \mathrm{C} /{ }^{12} \mathrm{C}$ of $2.5 \times 10^{-15}$ or 48,000 yr after molecular background correction. The scatter in the data comes mainly from the fact that the samples were prepared on 3 different graphitization systems over a relatively long time. For 1 set of samples prepared and measured together, the variation is significantly less.

counts were initially collected in a two-parameter $\Delta \mathrm{E}$-E spectrum gained using a gas ionization detector (Suter et al. 2007). Only the counts within a polygonal gate in the two-dimensional $\Delta \mathrm{E}-\mathrm{E}$ plot were accepted. Recently, we switched to a one-parameter $(\Delta \mathrm{E})$ measurement with a single channel analyzer (Schulze-König et al. 2010).

\section{Data Analyses}

Data analyses are performed with a computer program called BATS, described in detail by Wacker et al. (2010a). In short, the following steps were applied for the data reduction:

1. Molecular background subtraction, based on the measured ${ }^{13} \mathrm{C}_{\mathrm{H}}$;

2. Blank subtraction;

3. Fractionation correction using the measured ${ }^{13} \mathrm{C} /{ }^{12} \mathrm{C}\left(\delta^{13} \mathrm{C}\right)$ of the corresponding ${ }^{14} \mathrm{C} /{ }^{12} \mathrm{C}$ ratio;

4. Standard normalization using all standards.

The program also visualizes the data and verifies the quality of the acquired data with statistical tests. It also takes into account an additional uncertainty, reflecting the reproducibility of the results of the individual samples, and combines it with the uncertainty due to counting statistics, standard normalization, and blank correction. BATS is used to evaluate the data even while measurements are under way. The program evaluates the data without any user input within a few seconds and shows immediately if the desired precision has been reached and the measurement can be stopped. 


\section{DISCUSSION}

\section{Background and Blank}

In the gas ionization detector, we observe a molecular background of ${ }^{12} \mathrm{C}^{+}$and ${ }^{13} \mathrm{C}^{+}$corresponding to typically to 0.004 to 0.006 fraction modern carbon $\left(\mathrm{F}^{14} \mathrm{C}\right)$, which is about twice the real ${ }^{14} \mathrm{C}^{+}$of a typical processing blank. Although we have installed a 2-parameter gas ionization detector system (Suter et al. 2007) on MICADAS, we cannot separate the background from real ${ }^{14} \mathrm{C}$ counts. Only a slight shift of the fitted peak center can be observed, which can only be used for diagnostics and not for data evaluation of real measurements.

The background derives from molecules with mass $14\left({ }^{13} \mathrm{CH}^{-}\right.$or $\left.{ }^{12} \mathrm{CH}_{2}^{-}\right)$that are broken up in the stripper. A charge exchange from $2+$ to $1+$ in the second accelerator part is then likely responsible for the additional gained energy of the ${ }^{13} \mathrm{C}$ or ${ }^{12} \mathrm{C}$ ions, which is required to pass the electrostatic analyzer. The energy measured in the gas detector confirms this assumption. An additional angular scatter is possibly responsible that the ions first also pass the magnet, which in principle separates ions of different momenta.

The molecular background in the detector is dominated by ${ }^{13} \mathrm{C}$. However, ${ }^{12} \mathrm{C}$ can also get through the high-energy filter, which was confirmed by a measurement of graphite reduced with deuterium instead of normal hydrogen. In this case, ${ }^{12} \mathrm{C}$ is injected at the low-energy side as ${ }^{12} \mathrm{CD}^{-}$, which can be estimated to be about 100 times more abundant than ${ }^{12} \mathrm{CH}_{2}{ }^{-}$(based on observed ${ }^{12} \mathrm{CH}^{-} /{ }^{12} \mathrm{CH}_{2}{ }^{-}$ ratios at the low-energy side). The result was a $50 \times$ increased molecular background in the detector $\left(0.3 \mathrm{~F}^{14} \mathrm{C}\right)$. However, the ${ }^{12} \mathrm{C}^{+}$current measured at the high-energy side during mass-14 injection was about 10 times lower than the ${ }^{13} \mathrm{C}^{+}$current. The molecular background therefore scales with the measured ${ }^{13} \mathrm{C}^{+}$current from broken-up ${ }^{13} \mathrm{CH}^{-}$molecules (Synal et al. 2007). This ${ }^{13} \mathrm{C}^{+}$current is measured in a separate Faraday cup between the ${ }^{12} \mathrm{C}$ and the ${ }^{13} \mathrm{C}$ cup on the high-energy side (Synal et al. 2000). The correlation between this normalized molecular current $\left({ }^{13} \mathrm{C}_{\mathrm{H}} /{ }^{12} \mathrm{C}\right)$ and the ${ }^{14} \mathrm{C} /{ }^{12} \mathrm{C}$ is shown in Figure 2 to be stable over time.

Typically, we see that the molecular background-corrected blanks of $0.002-0.003 \mathrm{~F}^{14} \mathrm{C}$ show a standard deviation of $0.0003 \mathrm{~F}^{14} \mathrm{C}$ for high-precision measurements (with long data acquisition time) and $0.0005 \mathrm{~F}^{14} \mathrm{C}$ for normal samples. The reason for this difference is that high-precision samples are always measured directly after preparation, whereas normal samples may be stored for up to 2 weeks, which seems to influence the blank variability. Additionally, any surface contamination from sample pressing has less influence on a long measurement compared to a short one. The measurement of 50,000-yr-old samples is possible with the background correction, whereas without this correction, the limit is $45,000 \mathrm{yr}$ (calculated as twice the blank variability).

\section{Stability and Reproducibility}

The tuning of MICADAS for ${ }^{14} \mathrm{C}$ measurements is straightforward and once the system is tuned, it is very stable over time and rarely needs any retuning. The high stability is demonstrated in Figure 2, where the measurements of all OXII standards over a time period of 19 days are plotted (typically about 4 fresh OXII standards were mounted in cassette). During this time, the MICADAS system was not retuned. On the 16th and the 17th day, a gas measurement was performed and afterwards the same settings we had before for solid samples were reloaded (no tuning!).

The data points in the top pane (1) of Figure 2 show the measured raw ratio of ${ }^{14} \mathrm{C} /{ }^{12} \mathrm{C}$ with a scatter of $7.4 \%$, which is significantly higher than what can be expected from the counting statistics (4.3\%). The reason for this discrepancy lies mainly in the isotopic fractionation of the samples. The graphite produced in the individual graphitization system can change up to $10 \%$ in the ${ }^{13} \mathrm{C} /{ }^{12} \mathrm{C}$ ratio 


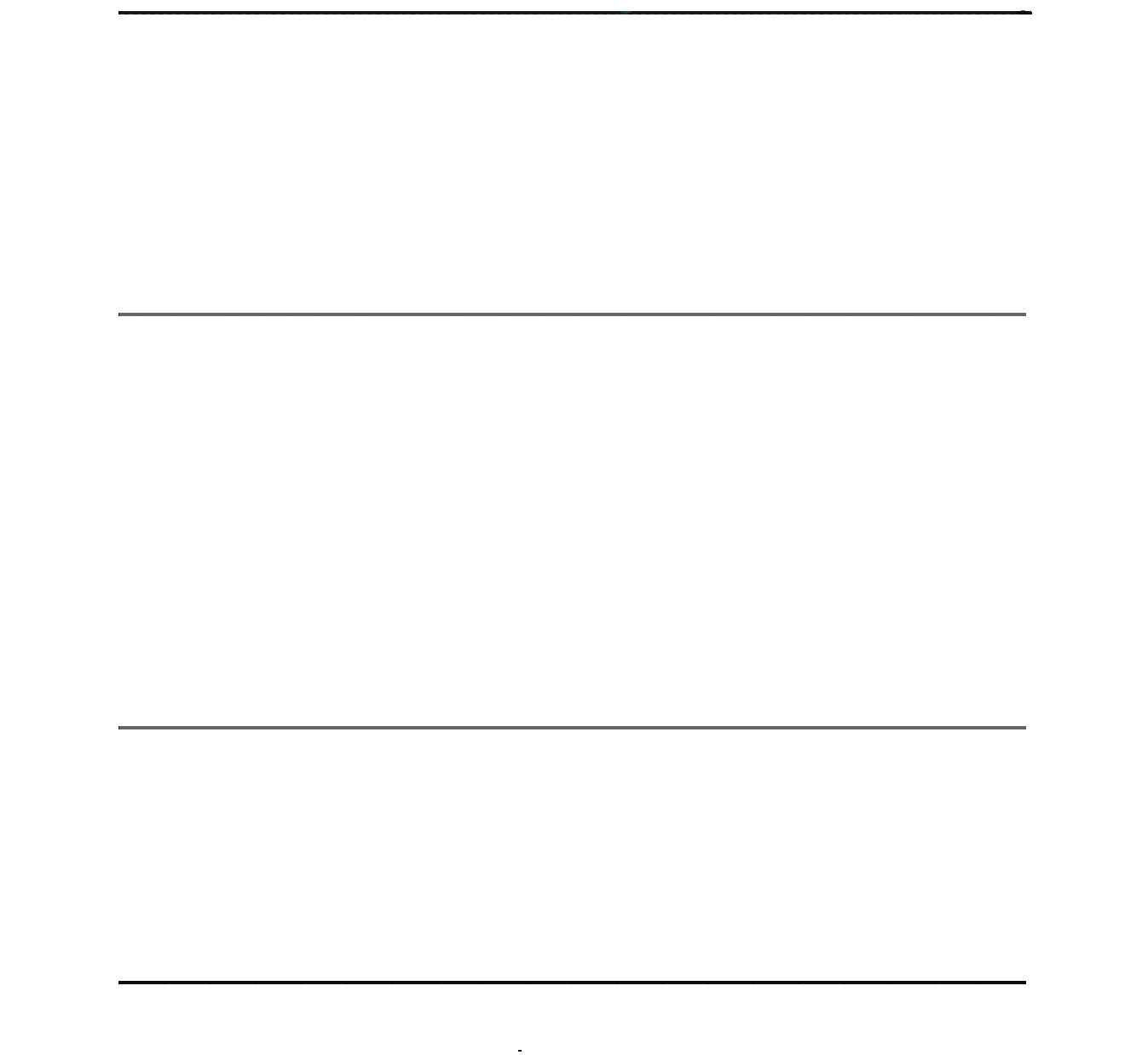

Figure 2 Raw ${ }^{14} \mathrm{C} /{ }^{12} \mathrm{C}$ ratios over time of single measurements of the OXII standard are shown in the top pane (1). In the second pane, the ${ }^{14} \mathrm{C} /{ }^{12} \mathrm{C}$ ratio corrected for the ${ }^{13} \mathrm{C} /{ }^{12} \mathrm{C}$ ratio is shown, once for the ${ }^{14} \mathrm{C}$ counts accepted by the single channel analyzer (2) and once the ${ }^{14} \mathrm{C}$ counts in the gate of the $2 \mathrm{D}$-spectra from the gas ionization detector (3). The measured ${ }^{13} \mathrm{C} /{ }^{12} \mathrm{C}$ ratio is shown in the lower pane (4). The vertical lines separate the measurements of a set of samples in 1 cassette.

between samples and thus about twice as much for the ${ }^{14} \mathrm{C} /{ }^{12} \mathrm{C}$ ratio. If the ${ }^{14} \mathrm{C} /{ }^{12} \mathrm{C}$ ratios are then corrected for fractionation with the measured ${ }^{13} \mathrm{C} /{ }^{12} \mathrm{C}$ (shown in the lower panel (4) of Figure 1) as shown in the middle panel (3) of Figure 1, the scatter is $4.7 \%$, only slightly higher than expected from counting statistics. This demonstrates that MICADAS is extremely stable over days without any drifts in the ratios, and that it is possible to reliably correct for any fractionation from the sample preparation.

The bottom data points in the middle panel (3) of Figure 2 show also the ${ }^{13} \mathrm{C} /{ }^{12} \mathrm{C}$ corrected ${ }^{14} \mathrm{C} /{ }^{12} \mathrm{C}$ ratio. However, here the two-dimensional gating for the ${ }^{14} \mathrm{C}$ particle identification was used instead of gating with the single channel analyzer. It is obvious that a small trend over days is now visible and $\sim 3 \%{ }^{14} \mathrm{C}$ counts are lost, because the residual energy signal may drop below the low level discriminator that cuts off the noise. We ceased using the two-dimensional gating because the positive influence on the background level was only minor $(-5 \%)$ while the simple gating with the single channel analyzer resulted in an increased yield (+3\%) and better long-term stability (see Figure 2 ). 
The cassettes 7, 12, and 16 shown in Figure 2 were high-precision measurements where 20 samples were measured over 2 days to about $700,000{ }^{14} \mathrm{C}$ counts. These samples were graphitized on the latest fully automated graphitization system (Wacker et al. 2010b) and tend to show much lower variation in fractionation than other samples prepared on a semi-automated system (all other cassettes).

The performance in routine analyses is given in Figure 3 on measurements of IAEA-C5 and IAEA$\mathrm{C} 3$ samples. The mean measured value for the IAEA-C3 of $(0.2301 \pm 0.00034) \mathrm{F}^{14} \mathrm{C}$ is in good
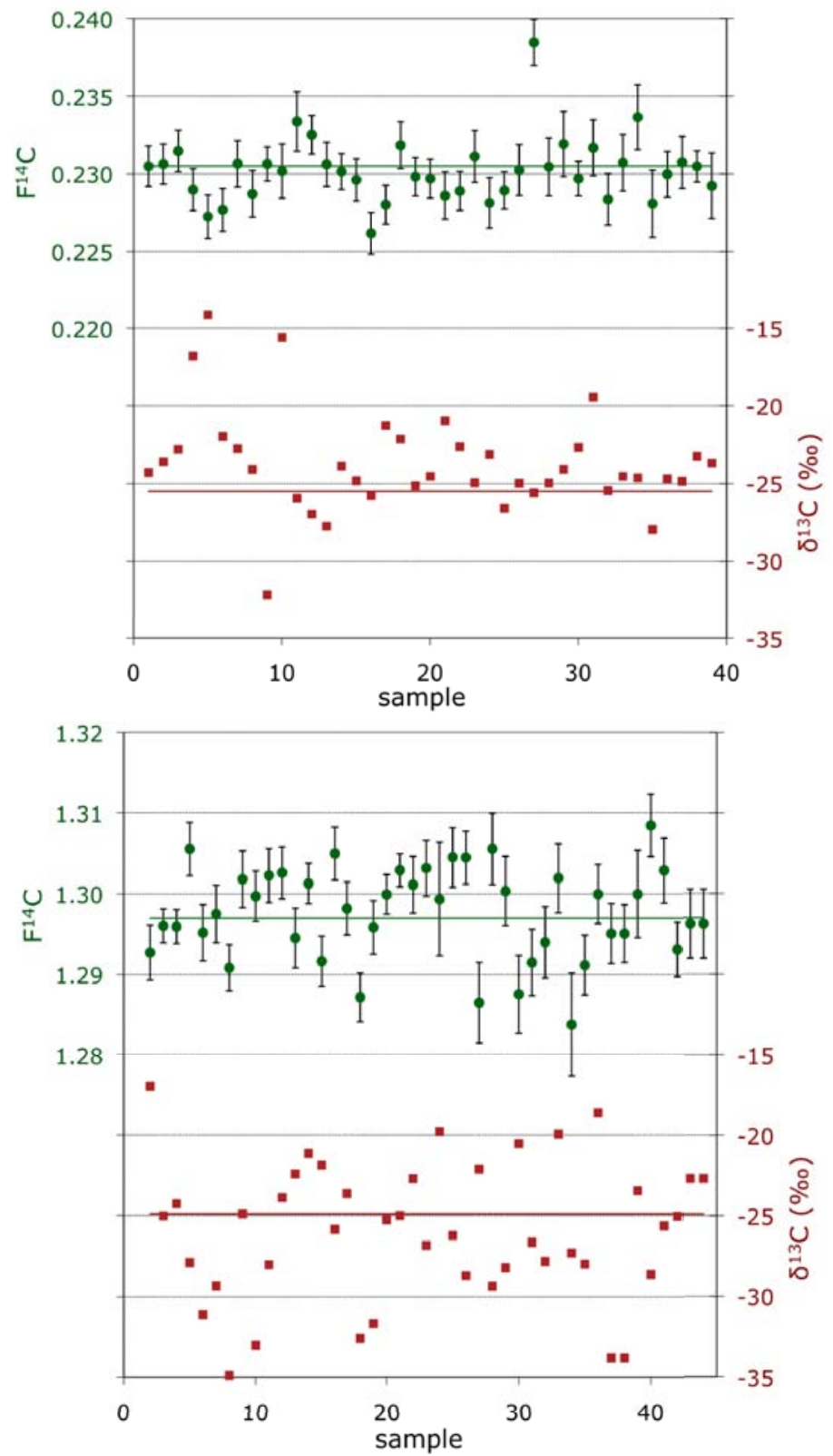

Figure 3 Measurements of the reference materials IAEA-C5 and IAEA-C3 during routine operation are presented. The solid line represents the reference value. The full circles on top are the $\mathrm{F}^{14} \mathrm{C}$ values and the squares below are the corresponding $\delta^{13} \mathrm{C}$ values. 
agreement with the reference value of $(0.2305 \pm 0.0002) \mathrm{F}^{14} \mathrm{C}$. The standard deviation of these measurements is with $0.0021 \mathrm{~F}^{14} \mathrm{C}$ only slightly higher than the mean uncertainty from counting statistics and the blank correction for a single measurement $\left(0.0015 \mathrm{~F}^{14} \mathrm{C}\right)$. Also, the IAEA-C3 value of $(1.298 \pm 0.001) \mathrm{F}^{14} \mathrm{C}$ is in perfect agreement with the reference value of $(1.297 \pm 0.001) \mathrm{F}^{14} \mathrm{C}$. Here, the standard deviation of the measurements $\left(0.006 \mathrm{~F}^{14} \mathrm{C}\right)$ is significantly higher than the uncertainty from the counting statistics and the blank correction of $0.004 \mathrm{~F}^{14} \mathrm{C}$. We therefore conclude that for our routine measurements, we have an additional unknown uncertainty for the sample reproducibility (external uncertainty) of 3\%. This uncertainty is added to all our routine measurements (Wacker et al. 2010a).

\section{Precision}

The MICADAS performs very well in high-precision measurements. Figure 4 shows the measured ratios of the 4 OXII standards we use for normalization of a set of samples. These standards were all measured to about $1 \%$ counting statistics. The presented fractionation-corrected ${ }^{14} \mathrm{C} /{ }^{12} \mathrm{C}$ ratios show a distribution that is basically defined by counting statistics. All high-precision measurements indicate that the theoretical limit for the reproducibility of the standards is well below $1 \%$. At the beginning of a measurement, a slight surface contamination (increased blank) sometimes causes a small additional scatter in the measurements of a single sample, but high-precision measurements over long time periods seem to have less scatter in addition to the counting statistics of ${ }^{14} \mathrm{C}$. This means an increased measurement time not only shows a higher counting statistics, but also seems to be more reliable.

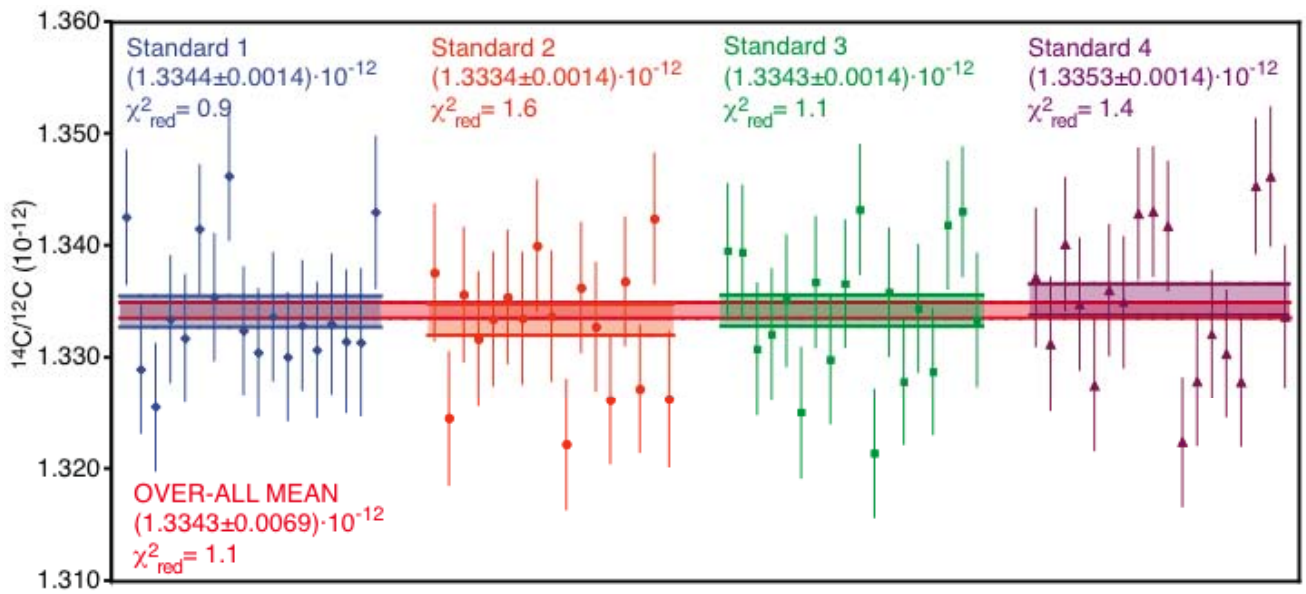

Figure $4{ }^{14} \mathrm{C} /{ }^{12} \mathrm{C}$ ratios of 4 OXII standards (17 passes) in a high precision measurement are shown. Each standard is measured to $\sim 1 \%$ counting statistics. The bars indicate the $1-\sigma$ range of the corresponding mean values.

The reproducibility of high-precision measurements on 2 real samples is given in Table 2. Both samples, a parchment and a seal cord from the Middle Ages, were each cleaned twice and graphitized 4 or 5 times, respectively, on the 2 different graphitization systems at ETH (Hajdas et al. 2004; Wacker et al. 2010b). Subsamples of the 2 samples show 2 distinct ages with a perfect repeatability within their final uncertainties of $\sim 20 \mathrm{yr}$ (2.5\%). This suggests that the subsamples of each sample can be averaged with an uncertainty of about 10 or $8 \mathrm{yr}(\sim 1 \%)$, respectively. The uncertainties of these mean values are lower than that of the calibration curve IntCal04 (Reimer et al. 2004), which has an uncertainty of $12-13 \mathrm{yr}$ in ${ }^{14} \mathrm{C}$ ages in this time range (with a decadal resolution in the samples entering IntCal04). 
Table 2 List of the single measurements of the parchment and the seal cord with their mean values, given in ${ }^{14} \mathrm{C}$ yr BP with $\pm 1-\sigma$ uncertainties. The $\delta^{13} \mathrm{C}$ is the measured isotopic ratio of the prepared graphite and not necessarily of the original sample.

\begin{tabular}{llll}
\hline Lab number & Sample type & ${ }^{14} \mathrm{C}$ age $(\mathrm{yr} \mathrm{BP})$ & $\delta^{13} \mathrm{C}(\%)$ \\
\hline ETH-36716.1 & parchment & $888 \pm 20$ & $-22.6 \pm 1.1$ \\
ETH-36716.2 & parchment & $878 \pm 19$ & $-20.7 \pm 1.1$ \\
ETH-36716.3 & parchment & $882 \pm 19$ & $-23.9 \pm 1.1$ \\
ETH-36716.4 & parchment & $875 \pm 19$ & $-22.3 \pm 1.1$ \\
ETH-36716 & parchment & $\mathbf{8 8 1} \pm \mathbf{1 0}$ & $-\mathbf{2 2 . 4} \pm \mathbf{0 . 6}$ \\
ETH-36717.1 & seal cord & $800 \pm 20$ & $-24.0 \pm 1.1$ \\
ETH-36717.2 & seal cord & $808 \pm 19$ & $-29.1 \pm 1.1$ \\
ETH-36717.3 & seal cord & $833 \pm 18$ & $-25.5 \pm 1.1$ \\
ETH-36717.4 & seal cord & $808 \pm 18$ & $-27.1 \pm 1.1$ \\
ETH-36717.5 & seal cord & $800 \pm 17$ & $-27.7 \pm 1.1$ \\
ETH-36717 & seal cord & $\mathbf{8 0 9} \pm \mathbf{8}$ & $-\mathbf{2 6 . 7} \pm \mathbf{0 . 9}$ \\
\hline
\end{tabular}

Therefore, it was decided to remeasure dendrochronologically dated tree-ring samples of the southern German oak chronology (Friedrich et al. 2004) in the time range of 1000 to 1200 calendar yr BP; the results are given in Table 3 . The samples, covering $5 \mathrm{yr}$ each, were measured to a precision of about 15 yr (2\%), including an uncertainty for the sample preparation of $0.8 \%$. The sample-to-sample ${ }^{14} \mathrm{C}$ age variability (26 yr) is very low and compares very well with the decadal IntCal04 raw data in the same time range from the different labs (Pearson and Stuiver 1986; Stuiver et al. 1998; Hogg et al. 2002), which show a variability between 30 and 35 yr from sample to sample in 10-yr resolution. In principle, with our 5-yr resolution we are sampling some of the production signal caused by the 11-yr solar cycle (Stuiver and Braziunas 1993), hence the lower sample-to-sample variability in our data is unexpected.

Table 3 Results of measurements on 5-yr tree-ring samples of 2 oaks from Eichstaett, southern Germany (Eichstaett 18, AD 1111-1269; Eichstaett 9, AD 1271-1305). Uncertainties include both counting statistics and sample preparation.

\begin{tabular}{lll}
\hline Lab number & Age range yr AD & ${ }^{14}$ C age $(\mathrm{yr}$ BP) \\
\hline ETH-37133 & $1111-1115$ & $968 \pm 15$ \\
ETH-37134 & $1116-1120$ & $959 \pm 15$ \\
ETH-37135 & $1121-1125$ & $955 \pm 15$ \\
ETH-37136 & $1126-1130$ & $939 \pm 15$ \\
ETH-37137 & $1131-1135$ & $954 \pm 15$ \\
ETH-37138 & $1136-1140$ & $966 \pm 14$ \\
ETH-37139 & $1141-1145$ & $959 \pm 14$ \\
ETH-37140 & $1146-1150$ & $960 \pm 14$ \\
ETH-37141 & $1151-1155$ & $926 \pm 15$ \\
ETH-37142 & $1156-1160$ & $927 \pm 15$ \\
ETH-37143 & $1161-1165$ & $895 \pm 15$ \\
ETH-37144 & $1166-1170$ & $899 \pm 14$ \\
ETH-37145 & $1171-1175$ & $909 \pm 15$ \\
ETH-37146.1 & $1176-1180$ & $945 \pm 15$ \\
ETH-37146.2 & $1176-1180$ & $920 \pm 14$ \\
ETH-37147.1 & $1181-1185$ & $909 \pm 15$ \\
ETH-37147.2 & $1181-1185$ & $868 \pm 14$ \\
ETH-37148 & $1186-1190$ & $882 \pm 14$ \\
ETH-37149 & $1191-1195$ & $899 \pm 14$
\end{tabular}


Table 3 Results of measurements on 5-yr tree-ring samples of 2 oaks from Eichstaett, southern Germany (Eichstaett 18, AD 1111-1269; Eichstaett 9, AD 1271-1305). Uncertainties include both counting statistics and sample preparation. (Continued)

\begin{tabular}{lll}
\hline Lab number & Age range yr AD & ${ }^{14} \mathrm{C}$ age $(\mathrm{yr} \mathrm{BP})$ \\
\hline ETH-37150 & $1196-1200$ & $909 \pm 14$ \\
ETH-37151 & $1201-1205$ & $909 \pm 15$ \\
ETH-37152 & $1206-1210$ & $885 \pm 14$ \\
ETH-37153 & $1211-1215$ & $849 \pm 14$ \\
ETH-37154 & $1216-1220$ & $899 \pm 14$ \\
ETH-37155.1 & $1221-1225$ & $867 \pm 15$ \\
ETH-37155.2 & $1221-1225$ & $869 \pm 14$ \\
ETH-37156.1 & $1226-1230$ & $875 \pm 14$ \\
ETH-37156.2 & $1226-1230$ & $875 \pm 14$ \\
ETH-37157.1 & $1231-1235$ & $807 \pm 14$ \\
ETH-37157.2 & $1231-1235$ & $829 \pm 15$ \\
ETH-37158.1 & $1236-1240$ & $863 \pm 14$ \\
ETH-37158.2 & $1236-1240$ & $843 \pm 15$ \\
ETH-37159.1 & $1241-1245$ & $819 \pm 14$ \\
ETH-37159.2 & $1241-1245$ & $805 \pm 15$ \\
ETH-37160 & $1246-1250$ & $837 \pm 14$ \\
ETH-37161 & $1251-1255$ & $821 \pm 15$ \\
ETH-37162 & $1256-1260$ & $813 \pm 17$ \\
ETH-37163 & $1261-1265$ & $790 \pm 15$ \\
ETH-37164 & $1266-1269$ & $775 \pm 14$ \\
ETH-37165 & $1271-1275$ & $748 \pm 14$ \\
ETH-37166 & $1276-1280$ & $757 \pm 14$ \\
ETH-37167 & $1281-1285$ & $723 \pm 14$ \\
ETH-37168 & $1286-1290$ & $734 \pm 14$ \\
ETH-37169 & $1291-1295$ & $704 \pm 14$ \\
ETH-37170 & $1296-1300$ & $705 \pm 14$ \\
ETH-37171 & $1301-1305$ & $702 \pm 14$ \\
\hline
\end{tabular}

Though the data set looks very consistent, we see on average a significant offset of $26 \mathrm{yr}$ ( $3 \%$ ) to the calibration curve (see Figure 5). At present, we cannot explain this offset as all our measurements of secondary standards agree fully with the consensus values (see e.g. Figure 3). We do not know if the offset originates from systematic effects of our measurement procedures. Some of the wood samples presented were also treated with a simple acid-base-acid procedure for comparison and do not show the 26-yr offset (Němec et al. 2010). The applied rigorous pretreatment with baseacid-base-acid-bleaching could therefore be responsible for the observed offset.

\section{CONCLUSIONS AND OUTLOOK}

The operation of the mini carbon dating system MICADAS is extremely stable over time and no user interaction is required over several days. The stability of the measurements over time allows us to make even highest-precision measurements that until recently were a niche for gas counters (Kromer and Münnich 1992) and advanced liquid scintillation facilities. It goes beyond high-precision measurements on large accelerators which suggest that modern samples can be measured down to a precision of 2\%o (Graven et al. 2007; Meijer et al. 2006). 


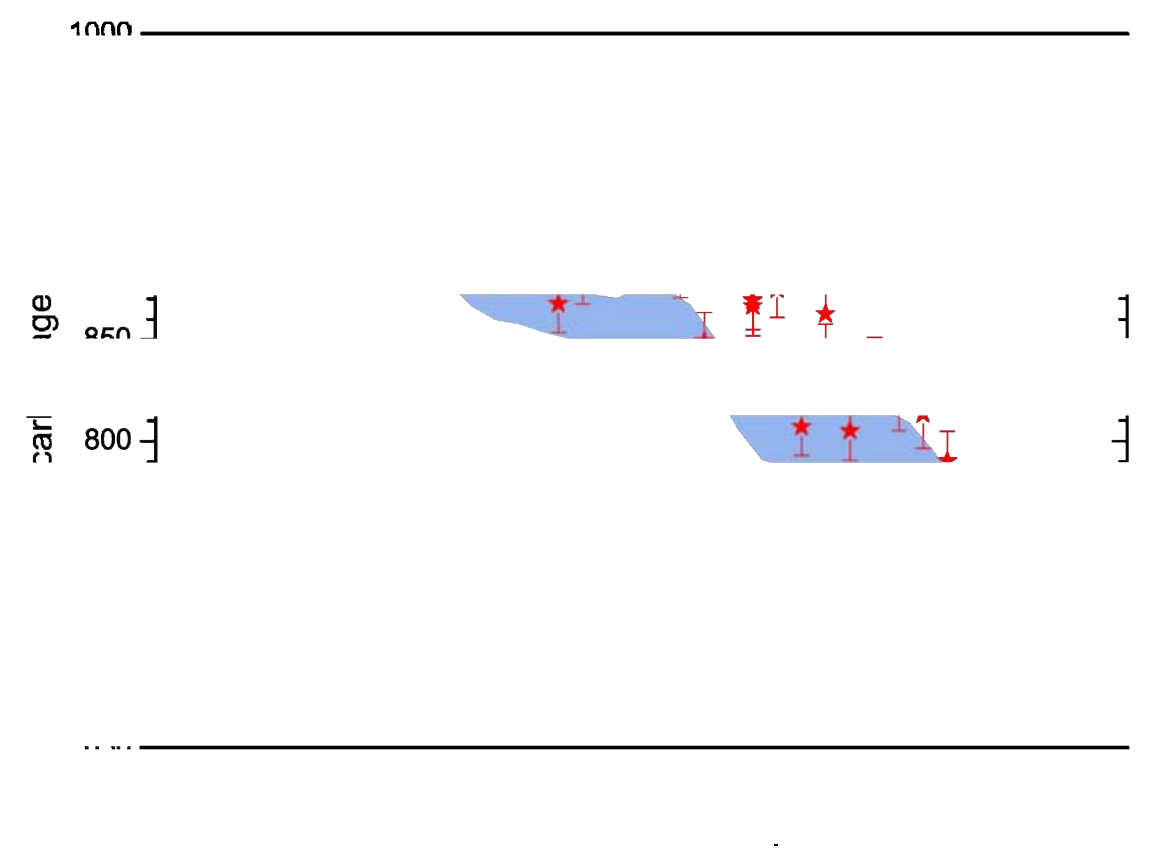

Figure 5 The 5-yr oak tree-ring samples from southern Germany samples measured at ETH Zurich are plotted with 1- $\sigma$ uncertainties together with the IntCal04 (Reimer et al. 2004) calibration band (also 1- $\sigma$ ).

The sample-to-sample variation is only $3 \%$; however, an offset of about $3 \%$ can be observed.

As a word of caution, we have seen a significant offset in our data when remeasuring the calibration curve. This discrepancy will be investigated further to clarify whether this offset is a yet unknown systematic effect of our measurement procedures or whether it depends on the applied pretreatment.

Improvements are still possible and desirable. For example, high-precision measurements require high counting statistics and hence need a long measurement time. Higher ion currents from the ion source are thus desired. Therefore, we are now replacing the prototype ion source from the MICADAS with a modified source, successfully used on the BioMICADAS (Schulze-König et al. 2010). This should allow us to run the source with $2-3$ times higher $\mathrm{C}^{-}$currents.

\section{ACKNOWLEDGMENTS}

We thank Peter Martig and Barbara Studer from the Archives of the City State of Berne for providing us the valuable parchment and seal cord samples that we used for high-precision dating.

\section{REFERENCES}

Bonani G, Beer J, Hofmann H, Synal H-A, Suter M, Wolfli W, Pfleiderer C, Kromer B, Junghans C, Münnich KO. 1987. Fractionation, precision and accuracy in ${ }^{14} \mathrm{C}$ and ${ }^{13} \mathrm{C}$ measurements. Nuclear Instruments and Methods in Physics Research B 29(1-2):87-90.

Friedrich M, Remmele S, Kromer B, Hofmann J, Spurk M, Kaiser KF, Orcel C, Kuppers M. 2004. The 12,460year Hohenheim oak and pine tree-ring chronology from central Europe-a unique annual record for ra-

diocarbon calibration and paleoenvironment reconstructions. Radiocarbon 46(3):1111-22.

Graven HD, Guilderson TP, Keeling RF. 2007. Methods for high-precision ${ }^{14} \mathrm{C}$ AMS measurement of atmospheric $\mathrm{CO}_{2}$ at LLNL. Radiocarbon 49(2):349-56.

Hajdas I, Bonani G, Thut J, Leone G, Pfenninger R, Maden C. 2004. A report on sample preparation at the ETH/PSI AMS facility in Zurich. Nuclear Instruments and Methods in Physics Research B 223-224:267-71. 
Hogg AG, McCormac FG, Higham TFG, Reimer PJ, Baillie MGL, Palmer JG. 2002. High-precision radiocarbon measurements of contemporaneous tree-ring dated wood from the British Isles and New Zealand: AD 1850-950. Radiocarbon 44(3):633-640.

Kromer B, Münnich K-O. 1992. $\mathrm{CO}_{2}$ gas proportional counting in radiocarbon dating - review and perspective. In: Taylor RE, Long A, Kra RS, editors. Radiocarbon after Four Decades. New York: Springer-Verlag. p 184-97.

Meijer HAJ, Pertuisot MH, van der Plicht J. 2006. Highaccuracy ${ }^{14} \mathrm{C}$ measurements for atmospheric $\mathrm{CO}_{2}$ samples by AMS. Radiocarbon 48(3):355-72.

Němec N, Wacker L, Hajdas I, Gäggeler H. 2010. Alternative methods for cellulose preparation for AMS measurement. Radiocarbon 52(2-3):1358-70.

Pearson GW, Stuiver M. 1986. High-precision calibration of the radiocarbon time scale, 500-2500 BC. Radiocarbon 28(2B):839-62.

Reimer PJ, Baillie MGL, Bard E, Bayliss A, Beck JW, Bertrand CJH, Blackwell PG, Buck CE, Burr GS, Cutler KB, Damon PE, Edwards RL, Fairbanks RG, Friedrich M, Guilderson TP, Hogg AG, Hughen KA, Kromer B, McCormac G, Manning S, Bronk Ramsey C, Reimer RW, Remmele S, Southon JR, Stuiver M, Talamo S, Taylor FW, van der Plicht J, Weyhenmeyer CE. 2004. IntCal04 terrestrial radiocarbon age calibration, 0-26 cal kyr BP. Radiocarbon 46(3):1029-58.

Ruff M, Wacker L, Gäggeler HW, Suter M, Synal H-A, Szidat S. 2007. A gas ion source for radiocarbon measurements at $200 \mathrm{kV}$. Radiocarbon 49(2):307-14.

Ruff M, Gäggeler HW, Suter M, Synal H-A, Szidat S, Wacker L. 2010. Gaseous radiocarbon measurements of small samples. Nuclear Instruments and Methods in Physics Research B 268(7-8):790-4.

Schulze-König T, Dueker SR, Giacomo J, Suter M, Vogel JS, Synal H-A. 2010. BioMICADAS: compact next generation AMS system for pharmaceutical science. Nuclear Instruments and Methods in Physics Research B 268(7-8):891-4.
Stuiver M, Braziunas TF. 1993. Sun, ocean, climate and atmospheric ${ }^{14} \mathrm{CO}_{2}$ : an evaluation of causal and spectral relationships. Holocene 3(4):289-305.

Stuiver M, Reimer PJ, Braziunas TF. 1998. High-precision radiocarbon age calibration for terrestrial and marine samples. Radiocarbon 40(3):1127-51.

Suter M, Balzer R, Bonani G, Hofmann H, Morenzoni E, Nessi M, Wölfli W, Andree M, Beer J, Oeschger H. 1984a. Precision measurements of ${ }^{14} \mathrm{C}$ in AMSsome results and prospects. Nuclear Instruments and Methods in Physics Research B 5(2):117-22.

Suter M, Balzer R, Bonani G, Wölfli W. 1984b. A fast beam pulsing system for isotope ratio measurements. Nuclear Instruments and Methods in Physics Research B 5(2):242-6.

Suter M, Dobeli M, Grajcar M, Muller A, Stocker M, Sun GY, Synal H-A, Wacker L. 2007. Advances in particle identification in AMS at low energies. Nuclear Instruments and Methods in Physics Research B 259(1): 165-72.

Synal H-A, Jacob S, Suter M. 2000. The PSI/ETH small radiocarbon dating system. Nuclear Instruments and Methods in Physics Research B 172(1-4):1-7.

Synal H-A, Stocker M, Suter M. 2007. MICADAS: a new compact radiocarbon AMS system. Nuclear Instruments and Methods in Physics Research B 259(1): $7-13$.

Unkel I. 2006. AMS-14C-Analysen zur Rekonstruktion der Landschafts- und Kulturgeschichte in der Region Palpa (S-Peru) [PhD thesis]. University of Heidelberg. www.ub.uni-heidelberg.de/archiv/6311. In German.

Wacker L, Christl M, Synal H-A. 2010a. Bats: a new powerful tool for AMS data reduction. Nuclear Instruments and Methods in Physics Research B 268(7-8): 976-9.

Wacker L, Němec M, Bourquin J. 2010b. A revolutionary graphitisation system: fully automated, compact and simple. Nuclear Instruments and Methods in Physics Research B 268(7-8):931-4. 